\title{
Comunicación

\section{La investigación del futbol y sus nexos con los estudios de comunicación. Aproximaciones y ejemplos}

Social research on football soccer and its links to communication studies. Approaches and examples

\author{
GUILLERMO ALONSO MENESES Y \\ JUAN MANUEL AVALOS GONZÁLEZ1
}

La investigación del futbol desde las ciencias sociales tuvo un proceso lento a lo largo del siglo XX y los estudios de comunicación también lo abordaron tardíamente. Sin embargo existen vínculos temáticos, conceptuales y metodológicos. El artículo hace una revisión de la literatura más significativa, construye una problematización del futbol mediatizado y propone algunos elementos para construir la agenda futura.

PALABRAS CLAVE: Futbol, ciencias sociales, estudios de comunicación, medios, agenda.
The social sciences made a rather timid progress in researching football soccer during the twentieth century, an aspect which extended to the efforts of media and communication studies to investigate the world's most popular sport. Nevertheless, as an area of academic endeavour, media and communication studies developed themes, methods and concepts which are here reviewed, and taken as a point of departure for a future research agenda of football as a mediated social phenomenon.

KEY WORDS: Football soccer, social sciences, communication and media studies, research agenda.

1 El Colegio de la Frontera Norte, México.

Correos electrónicos: gui@colef.mx; manusdec@colef.mx

Carretera Escénica Tijuana-Ensenada Km. 18.5, Col. San Antonio del Mar, C.P. 22560; Tijuana, Baja California, México. 
El futbol o sus triunfos, lo mismo pueden ser considerados un nuevo opio del pueblo o un aliciente para seguir luchando. La polémica es añeja y se exacerbó con la omnipresencia mediática del balompié, de modo que ahora existe una ingente cantidad de partidarios en uno y otro bando. Jorge Luis Borges fue de los que sentía aversión al futbol y Eduardo Galeano (1990) lo explica expresivamente cuando dice del bonaerense: "Le horroriza todo lo que reúne a la gente, como el futbol o la política, y todo lo que la multiplica, como el espejo o el acto del amor" (p. 119). Unas veces asociado al vulgo y a las masas, otras a su uso político como el nuevo panem et circences que desmoviliza o despolitiza, el futbol ha sido tachado de "intrínsecamente fascista" por el escritor Sánchez Ferlosio (1990) en "Un espectáculo fascista". Una afirmación que, meses después, fue refutada por el antropólogo Juan Aranzadi (1990) en "Deporte y fascismo", donde pedía distinguir entre el "carácter fascista de las actitudes personales y grupales de hooligans, tifosi, fanáticos de $s u$ equipo y aficionados a ver futbol en general (con la excepción de unos pocos estetas degustadores de la belleza del juego y la inteligencia de los jugadores)" (s. p.) y apuntaba que el fascismo en el futbol era "fruto de su profesionalización (que le somete a los imperativos del mercado y la publicidad)" (s. p.).

Este cruce de opiniones entre Ferlosio y Aranzadi en parte refleja un malestar debido a la excesiva atención que atrae el futbol y su uso por distintas instancias, desde políticos y empresarios con intereses cortoplacistas hasta las empresas de comunicación (estatales o privadas): los mass media o Medios de Comunicación Masivos (MCM). Al igual que el fascismo, tanto lo mercantil como su manipulación mediática le llegan al futbol "de fuera", y si los imperativos del mercado y la publicidad tienen tanto peso, como señala Aranzadi, se debe a la condición de artefacto cultural del futbol que lo hace susceptible de ser usado con distintas finalidades (Alonso, 1995). Apuntado esto, en este trabajo nos interesa sintetizar lo que ha sido la investigación del futbol y sus nexos con los estudios de comunicación, así como dar elementos para una agenda de investigación.

Sabemos que históricamente se dio un primer proceso donde el deporte en general y el futbol en particular tuvieron en los MCM un estatus relativamente diferenciado entre su condición de materia informativa 
y de materia de entretenimiento. Briggs y Burke (2002) señalaron que las "líneas divisorias entre información y entretenimiento" se fueron difuminando en las décadas de los cincuenta y sesenta del siglo XX, tanto en prensa como radio y televisión. Sin embargo, hoy en día ambas dimensiones pueden estar (con)fundidas al existir estilos o líneas editoriales que no las distinguen; su conformación va más allá del dictum "informar entreteniendo". Y esta indefinición, necesariamente, impacta en su investigación.

Por otra parte, distintas cadenas y canales de televisión como Fox Sports, ESPN, TDN en México o Gol Televisión en España ofrecen ininterrumpidas retransmisiones, horas y horas de programas deportivos, sin olvidar la copiosa información y literatura que generan el deporte y el futbol, fundamentalmente periodística: L'Equipe o Paris Match en Francia, Gazetta dello Sport en Italia, los diarios As y Marca en España, The Sun y Daily Mirror en Inglaterra (que no son diarios deportivos canónicos, sino los que tienen las secciones más amplias), A Bola en Portugal, Ovaciones, Record y Esto en México o el diario Olé y la revista $E l$ Gráfico en Argentina. La oferta en prensa, radio y televisión es tal que proyecta la imagen de un fenómeno sobrevalorado a la vez que sobreexplotado en exceso por los MCM.

A pesar de que la investigación del futbol desde las ciencias sociales, incluyendo los estudios de comunicación, se desarrollaron lentamente en el siglo XX, cabe precisar que hubo y hay vínculos temáticos, conceptuales y metodológicos que deben ser explorados. En este artículo hacemos una revisión de la literatura más significativa, construimos una problematización del futbol mediatizado y proponemos algunos elementos para construir la agenda futura en los estudios de comunicación.

BREVES ANTECEDENTES HISTÓRICOS: DE INGLATERRA A MÉXICO

La relación entre los MCM -en su sentido primigenio- y el deporte en general o el futbol en particular tiene más de 200 años; no vamos a retroceder miles de años para hablar de las manifestaciones de arte rupestre que recrean escenas de juegos o a la presencia de juegos competitivos en la obra homérica. Sabemos que hubo tempranas representaciones, proclamas, anuncios, referencias y publicaciones. Por comenzar arbi- 
trariamente con un ejemplo británico, el historiador Carl Diem (1966) recordó: "Por una proclama del alcalde de Londres, Nicholas Farndon, se prohibía en 1314 el juego del futbol en las plazas de Londres. La prohibición se repitió en 1365 y otra vez más al cabo de siete años" (T. I, p. 413). Otro ejemplo de publicación lo da Max Weber (1985) cuando habla de un Book of Sport que Jacobo I y Carlos I (reinaron en Inglaterra entre los siglos XVI-XVII) elevaron a ley con el fin de combatir el puritanismo; el libro llegó a ser leído desde los púlpitos, con la intención de promover la tolerancia de ciertos esparcimientos dominicales. "Y cuando el rey conminó con severos castigos todo ataque contra la legalidad de aquellos deportes, lo hacía precisamente con el fin de acabar con ese rasgo ascético que, por antiautoritario, parecía peligroso para el Estado" (p. 234). Estas dos noticias, no solo nos hablan de publicaciones, también de un debate sobre ciertas prácticas deportivas y su control por intereses ajenos a la naturaleza lúdica del deporte.

La primera revista exclusivamente deportiva apareció en 1821 en Inglaterra, Sporting Life, y por esas fechas también se generalizó la edición del libro de temática deportiva (Vinnai, 1974). Años después se publicó la obra de Delabere Pritchett Blaine, An Enciclopedia of Rural Sports, en 1840. Estos hitos hablan ya de una primitiva mediatización del deporte. Otras veces, el futbol puede ser rastreado como noticia en los periódicos. En 1865, la prensa "británica" de Buenos Aires, la que se publicaba en inglés -en concreto el periódico The Standard- ya hacía mención del futbol. Y eso que el primer club argentino de futbol se fundó en el año 1867: el Buenos Aires Cricket Club (Gispert, 1981). Recuérdese que en aquellos años el futbol dependía en buena medida de los clubes de cricket, un deporte con mayor prestigio entre las clases pudientes británicas; por eso a principios del siglo XX se fundó el México Cricket Club.

Precisamente la llegada y arraigo del futbol a México fue sintetizado por Enrique Krauze (1994). El nuevo sport lo trajeron los ingleses que desembarcaron en México con la ola de progreso impulsada en el porfiriato a principios del siglo XX. La presencia inglesa en los alrededores mineros de Pachuca, como Mineral del Monte y Real del Monte, o en las primeras fábricas de Orizaba, propició los primeros eventos organizados de football. La Ciudad de México pronto conoció los primeros club en los que se reunía la colonia de inmigrantes britá- 
nica, pues la semilla del futbol prendió de una manera muy parecida a como lo hizo en Buenos Aires o Montevideo algunas décadas antes, y en aquellos primeros clubes se practicó el cricket, el tenis y el polo; apunta Krauze (1994):

Un tal Mr. Blackmore importaba balones de Inglaterra. El embajador británico imponía las reglas, que obedecían fielmente los jugadores, súbditos todos de la Corona. Cuando los futbolistas ingleses se fueron a la guerra mundial, solo quedaron los entrenadores. Así empezó una historia deportiva que guarda paralelos sorprendentes con la historia del país ... A raíz de la guerra civil española llegaron los homólogos deportivos de Gaos, Bergamín, León Felipe, Cernuda: se llamaban Lángara, Zubieta, Regueiro, Iraragorri. Como aquellos filósofos y literatos en la esfera de los libros, los vascos enriquecieron el capítulo del balón (s. p.).

El futbol en México - como tantas otras cosas- desembarcó por el puerto de Veracruz y el juego fue contagiado por la colonia inmigrante inglesa que lo practicaba. El futbol de las islas británicas fue tanto el deporte de la clase obrera como de los alumnos de la aristocracia y de la alta burguesía (los snobs) que lo jugaban en los selectos college. De hecho México también conoce ambos vectores de expansión: los obreros de Orizaba y Pachuca, así como los burgueses y diplomáticos británicos de la capital. El impulso original lo dieron cinco equipos: Orizaba Athletic Club, Pachuca Athletic Club, Reforma Athletic Club, México Cricket Club y British Club, estos tres últimos capitalinos, que organizaron la Liga Mexicana de Football Amateur Association, resultando el Orizaba el primer campeón en 1902. A partir de ese entonces, el futbol institucionalizado en México, a pesar de la inestabilidad del periodo revolucionario, se consolidó en el periodo 1901-1943.

La inestabilidad social no permitió sino hasta 1921 la celebración de un torneo más amplio con 15 equipos en el Campeonato del Centenario (en 1821 se había consumado la Independencia). La Federación Mexicana de Football Association fue fundada en 1927 y fue inscrita en la Fédération Internationale de Football Association (FIFA), de ahí que México fuese una de las 13 selecciones participantes en el primer Mundial de Futbol celebrado en Uruguay en 1930. Pero no fue hasta 1943 
que se celebró el primer campeonato profesional. Durante ese periodo el futbol mexicano fue ganando un papel cada vez más importante tanto en la sociedad como en la prensa del centro-sur del país; en la franja que va desde Guadalajara a la Ciudad de México pasando por Pachuca, Córdoba y Orizaba.

Posteriormente, México fue el país organizador de los mundiales de 1970, donde se encumbra la primera figura futbolística global, O Rey Pelé, en un campeonato que dejó imágenes televisivas espectaculares, ya clásicas, como algunas jugadas de Pelé o el brazo en cabestrillo de Franz Beckenbauer, y también del Mundial de 1986 donde se encumbró el no menos mediático y global Diego Armando Maradona, quien dejó goles que forman parte de la videoteca de cualquier aficionado como los marcados por el astro argentino frente a Inglaterra. La marca Pelé alcanzó tal globalidad y éxito que todavía hoy es un reclamo publicitario apreciado, ya sea anunciando Viagra o productos del Banco Santander. Y detrás de ídolos como Pelé o Maradona, en aquellos mundiales están las no menos poderosas imágenes televisivas en color de sus goles y de ambos alzando la Copa del Mundo en el Estadio Azteca.

\section{EL DEPORTE Y EL FUTBOL DESDE}

\section{LA ANTROPOLOGÍA Y LA SOCIOLOGÍA}

El interés de las ciencias sociales por el deporte como fenómeno investigable fue tardío. George H. Sage (1984) en el capítulo "Sport in American society: Its pervasiveness and its study", texto recogido en la antología Sport in Contemporary Society de Eitzen (1984)2 que recapitula los primeros estudios sociológicos y antropológicos del deporte, considera que la obra pionera fue Sport und Kultur de H. Steinitzer, publicado en Alemania en 1910. Igualmente, Soziologie des Sports de Risse publicado en Berlín en 1921 está considerado el primer trabajo de sociología deportiva, una disciplina que conoció su empuje defini-

2 Eitzen señala que el propósito de su antología desde un punto de vista teórico y temático es promover una conflict perspective como reacción a una constatación: que el deporte ha devenido a fines dispares a los que en principio respondía. 
tivo tras la Segunda Guerra Mundial con obras como Sport and Society (Natan, 1958), Sport in Society (McIntosh, 1963) y Sociología del Deporte (Magnane, 1964/1966).

Según Sage (1984), el año 1964 fue definitivo por fundarse el International Committee for Sport Sociology afiliado a dos instituciones de la Organización de las Naciones Unidas para la Ciencia, la Educación y la Cultura (UNESCO): The International Council of Sport y la Physical Education and the International Sociological Association. Otro hito lo encontramos en 1968 con la obra de Michel Bouet, Signification du Sport, uno de los primeros en concebir el deporte como una forma autónoma e intrínseca de cultura. Precisamente, Thomas, Haumont y Levet (1988) conciben la obra de Bouet como clave porque aborda el deporte a partir de dos vertientes: como práctica deportiva y como actividad que cumple funciones. Por esas fechas también aparecen los primeros textos críticos de la nueva izquierda sobre deporte, como la obra de Luschen (1970), The Cross Cultural Analysis of Sport and Games (Thomas, Haumont \& Levet, 1988) o los trabajos de Partisans (1978).

Thomas, Haumont y Levet (1988) reconocen que la aparición de la sociología del deporte fue tardía, en parte debido a la resistencia del medio deportivo a ser analizado, tesis también apoyada por Jean-Marie Brohm (1982). Hechos, como que los resultados deportivos influían en la lucha ideológica entre el este y el oeste, la Guerra Fría entre la Unión Soviética y Estados Unidos, facilitaron el camino a la realización de una lectura sociológica del fenómeno deportivo.

La antropología es otra disciplina que ha aportado importantes obras en las últimas décadas. Para Norbeck (1986) los antropólogos Kendall Blanchard y Alice Cheska tienen derecho a ser considerados "los pioneros de la investigación antropológica del deporte" (p. 1), sin negar que puedan existir otros trabajos anteriores, por ejemplo, el de Edward B. Taylor (1879) "The History of Games". La Antropología del Deporte de Blanchard y Cheska (1985/1986) es un esfuerzo por interpretar las diferencias interculturales que se ponen de manifiesto en el ámbito del deporte, que presenta formas y significados distintos según las sociedades. Por eso, un deporte como el béisbol cobra unas formas y significados diferentes si se nos remite a Estados Unidos, a Japón o a México. Respecto del futbol, la obra colectiva en- 
cabezada por el antropólogo brasileño Roberto Da Matta (1982) Universo do Futebol: Esporte e Sociedade Brasileira fue de las primeras en vislumbrar la importancia de las formas socioculturales tributarias del balompié y su influencia en toda una nación.

Otra referencia fundamental en la antropología del deporte fue Play, Games and Sports in Cultural Contexts, un reading de Janet C. Harris y Roberta J. Park (1983) cuya "Introduction to the sociological study of play, games, and sports" es el antecedente más importante de Blanchard y Cheska (1985/1986), porque abordan problemas clásicos como la evolución de los estudios socioculturales del deporte, las definiciones y diferencias de sentido de play, games y sports, distintas estrategias de investigación antropológica, diferentes alternativas temáticas, etc. Ya en los años noventa un hito importante fue la obra multidisciplinar en forma de reading de Barreau y Morne (1991) Epistemología y Antropología del Deporte.

Esta breve enumeración de obras quedaría incompleta si no señalásemos el título de algunas producidas en español para tener una panorámica del auge de dichos estudios e investigaciones en nuestro idioma. Por ejemplo, las obras de Eduardo Archetti (1985) Fútbol y Ethos, o Archetti (2001) El Potrero, la Pista y el Ring. Las Patrias del Deporte Argentino; de Andrés Fábregas Puig (2001) Lo Sagrado del Rebaño. El Fútbol como Integrador de Identidades; de Pablo Alabarces (2002) Fútbol y Patria. El Fútbol y las Narrativas de la Nación en la Argentina, así como (2003) Futbologías. Fútbol, Identidad y Violencia en América Latina; de Medina y Sánchez (2003) Culturas en Juego. Ensayos de Antropología del Deporte en España. Más recientemente, Da Matta (2009) ha vuelto a recordar los nexos entre el futbol y la sociedad en "Sport in society. An essay on Brazilian football"; Gabriel Angelotti (2010) Chivas y Tuzos, o la más multidisciplinar de Alonso y Escala (2012) Offside/Fuera de Lugar. Fútbol y Migraciones en el Mundo Contemporáneo.

\section{EL DEPORTE, EL FUTBOL Y LOS ESTUDIOS DE COMUNICACIÓN}

El estudio de los medios de comunicación (media studies) y del deporte como objeto de estudio en el campo de la comunicación son dos tendencias de investigación que no han dejado de crecer. El nexo comunica- 
ción/deporte emerge entre las décadas de 1970 y 1980 (Wenner, 1989), y comenzaron a institucionalizarse en las universidades y centros de investigación en la década de 1990 (Bernstein \& Blain, 2002). ${ }^{3}$ Esta línea de investigación, así como la construcción del objeto de estudio entiende la comunicación como transmisión, con un significado que implica transferencia material e inmaterial de cosas. Dicha premisa subyace a los modelos de la comunicación masiva: emisor, mensaje, receptor, canal (Peters, 1999). Y cuando John B. Thompson (1990/1998) desarrolla el concepto de transmisión cultural, aproxima la experiencia mediática de producción e intercambio de formas simbólicas a la cuestión de los recursos técnicos que intervienen en dicho proceso. En síntesis, la mediatización deportiva se abordó desde presupuestos como estos.

Por otra parte, hay una corriente que aborda la comunicación en su impronta sociológica, deudora del concepto de interacción, que nos aproxima al entendimiento de las relaciones sociales en donde se anclan los procesos humanos de significación (Peters, 1999). Sobre esta premisa se basó la construcción de un nuevo objeto de estudio en comunicación desde una perspectiva sociocultural, encaminada a romper el reduccionismo comunicacionista del estudio del intercambio de mensajes legitimado en el origen campal de la comunicación (Fuentes, 2008). Este viraje entiende los MCM como una mediación tecnológica, entre otras facetas, lo que facilita el estudio del deporte desde la perspectiva sociocultural de la comunicación y permite enfatizar las interrelaciones entre las prácticas sociales y de entretenimiento, las negociaciones y los acuerdos sociales, con los artefactos culturales inmersos en el ámbito del deporte mediatizado. Estos dos conceptos de la comunicación (transmisión e interacción) no son excluyentes uno de otro y ofrecen herramientas interpretativas pertinentes a los temas derivados de la relación deporte y comunicación. ${ }^{4}$

3 Según Pablo Alabarces (2000), el entrecruce deporte/comunicación en Latinoamérica se da en la década de 1990 con los trabajos del grupo de Esporte e Mídia pertenecientes a la Sociedad Brasileña de Estudios de Comunicación.

4 Para una revisión sobre teoría y metodología para el estudio del deporte y comunicación desde los estudios culturales y el estudio de los medios véase David Rowe (2004b). 
Ahora bien, cuando el campo de la comunicación se define por su impronta interdisciplinaria coincide, tal como se señaló, con el hecho que también el estudio del deporte es multidisciplinario. Esta pluralidad disciplinar la vemos también en las redes y actores académicos en épocas y espacios geográficos distintos y distantes. Por ejemplo, Joaquín Marín (2005b) - de la Universidad de Sevilla- apunta que uno de los pioneros de referencia en España fue Miquel De Moragas desde el Centro de Estudios Olímpicos de la Facultad de Ciencias de la Comunicación de la Universidad Autónoma de Barcelona, creado a propósito de los Juegos Olímpicos de Barcelona 1992.

Así mismo, Brasil tiene tradición académica y escuelas en la prensa, la televisión o la publicidad para profundizar en las implicaciones sociales y culturales del deporte y el futbol, como los trabajos de Dalpiaz (2002) sobre sociedad del espectáculo; Gastaldo (2002) sobre publicidad y relaciones raciales; de Helal, Soares y Santoro (2004) sobre prensa, futbol y memoria. Más recientemente destacan Gastaldo $(2009,2011)$ sobre futbol mediatizado o comunicación y deporte, o Helal (2011) sobre la institucionalización académica en Brasil de los estudios sobre futbol y comunicación.

De igual manera destaca el grupo de Marli Hatje y Sergio Carvalho adscrito a la Universidad Federal de Santa Maria (Comunicação, Movimento e Mídia na Educação Física), mientras que en Argentina está el grupo de trabajo Comunicación y Deporte dirigido por Sergio Ricardo Quiroga del Centro de Estudios Olímpicos José Benjamín Zubiaur (Marín, 2005b). Debiendo mencionar al argentino Pablo Alabarces, coordinador del grupo Deporte y Sociedad del Consejo Latinoamericano de Ciencias Sociales (CLACSO) de 1999 a 2003; a Claudia Benassini y Enrique Rivera Guerrero en México y, recientemente, el grupo de investigación Comunicación y Deporte de la Asociación Mexicana de Investigadores de la Comunicación (AMIC) dirigido por Samuel Martínez de la Universidad Iberoamericana, entre otros. Sin olvidar el grupo de trabajo Mass Media de la Asociación Internacional para la Investigación en Medios y Comunicación (IAMCR, por sus siglas en inglés).

No obstante, todo apunta a que las publicaciones fundacionales del estudio del deporte y la comunicación se dieron en el mundo 
anglosajón, particularmente el estadounidense, la mayoría de veces en formato de readers, compilaciones de trabajos representativos de líneas de investigación que buscan exponer el estado actual de la pesquisa. En la década de 1980 destaca el libro Media, Sports, and Society (1989) compilado por Lawrence Wenner, donde se presenta el trabajo desarrollado sobre los temas de la producción en los medios de comunicación, los contenidos y las audiencias deportivas. En el capítulo "Media, sports, and society: The research agenda" resulta significativo, Wenner ofrece uno de los primeros balances de la producción académica sobre deporte y comunicación, presentando los debates campales y los avances de investigación de la época a manera de estado del arte (1989). Una década después se publica Sportcult editado por Toby Miller y Randy Martin (1999), libro que estudia la relación del deporte con los medios, el Estado y otras categorías sociales como el género y la etnicidad.

El siglo XXI lo inauguran Raymond Boyle de la Universidad de Glasgow y Richard Haynes de la Universidad de Stirling en Inglaterra (Escocia) con Power Play. Sport, the Media and Popular Culture (2000/2009), obra que ahonda la relación entre el deporte, los medios de comunicación y la cultura popular a través de categorías como identidad, etnicidad, género, consumo, industria cultural, el periodismo y la era digital. En 2004 se publica Critical Readings: Sport, Culture and the Media. Issues in Cultural and Media Studies editado por David Rowe (2004a), libro que presenta una mirada al complejo mediático y cultural deportivo a través de la industria de los medios de comunicación y las audiencias, prestándole especial atención tanto al proceso de producción (periodismo, televisión, mercadotecnia y publicidad) como al de recepción de contenidos deportivos.

Arthur Raney y Jennings Bryant coordinan Handbook of Sports and Media (2006) que presenta distintas investigaciones que engloban las diversas temáticas y facetas del estudio del deporte y los medios de comunicación organizados en cuatro ejes temáticos: a) el desarrollo y las representaciones del deporte en los medios (perspectiva histórica), b) el negocio de la cobertura del deporte mediatizado (industria cultural), c) las audiencias mediáticas deportivas y d) los temas clave del fenómeno del deporte mediatizado (globalización, etnicidad y género). 
A pesar de la distancia espacial y temporal entre las obras señaladas, producidas entre finales de la década de 1980 y durante la década de 2000, los autores se ubican en paradigmas teóricos y perspectivas de estudio compatibles. Es decir, las plataformas heurísticas desde las que abordaron y se objetivó el tema del deporte y la comunicación resultan vigentes. Obviamente, en todos estos años las investigaciones han tenido que integrar paulatinamente temas y debates nuevos, como la globalización o las nuevas tecnologías que inciden en los sistemas y redes de medios. Nuevos ítem clave para comprender los reacomodos en el complejo escenario deportivo/comunicacional (Bernstein \& Blain, 2002; Boyle \& Haynes, 2000/2009).

La producción académica entre 2000 y 2010 sobre deporte y comunicación tuvo una notable contribución en el artículo "Sport and the media: The emergence of a major research field" (2002) de Alina Bernstein y Neil Blain publicado en la revista Sport in Society. En él se articulan las discusiones y los aportes de diversos autores en torno al género, la identidad nacional, la etnicidad y la globalización definidos como los temas centrales o vertebradores en el estudio del deporte y los media. A este respecto, el dossier "Deporte y medios de comunicación" publicado por la revista Telos en 1994 marcó un hito, destacando el artículo "Deportes y medios de comunicación. Sinergias crecientes" de Miquel De Moragas, quien trata la influencia recíproca entre deporte y medios de comunicación, haciendo hincapié en el uso que la industria de los MCM hace del deporte desde su concepción como espectáculo. Igual de sugerente por el análisis de los lazos entre el deporte y los MCM desde la lógica económica del deporte es "Economía del deporte y de la televisión. Intereses complementarios" de Bourg y Nys (1994), que plantean que "la transformación de la televisión y la mundialización del deporte han multiplicado los intereses económicos mutuos" (s. p.).

El deporte y la televisión también fueron tratados por Elisabeth García, Miquel De Moragas y Miguel Gómez (1994) en "El deporte en las televisiones españolas. Un papel creciente en la programación”, en donde, desde el análisis de contenido, revisaron la presencia y peso del deporte en las programaciones. Marc Carroggio (1994) en "Patrocinio, comunicación y deporte. La audiencia, un oro que fusiona tres sectores" planteó la 
fuerza de la convergencia entre la inversión de patrocinios, los actores del deporte y los MCM que crea una fuente de ingresos fundamental para el deporte/espectáculo. Otro artículo que resalta por la pertinencia temática es "Los deportes en la era informática. Las tecnologías de la información en las emisiones deportivas" de James Larson (1994), sobre todo por la coyuntura que en la década de 1990 representó la aplicación e integración de la informática y las telecomunicaciones a los Juegos Olímpicos de Barcelona 1992 y Atlanta 1996 (De Pablos, 2005).

Más de una década después se publicó el libro Comunicación y Deporte. Nuevas Perspectivas de Análisis coordinado por Joaquín Marín Montín en 2005. La obra busca visibilizar las relaciones entre la comunicación y el deporte desde los principales ámbitos de estudio del campo comunicacional (Marín, 2005a). Destacan las reflexiones sobre el periodismo deportivo de Antonio Alcoba (2005), quien reivindica el papel del fotógrafo deportivo dentro del periodismo como una especialización autónoma o el análisis de contenido de Maritza Sobrados (2005), con relación a los géneros periodísticos de la prensa deportiva en España, distinguiendo la noticia explicativa, la noticia reportajeada (sic), el comentario del partido y el artículo anecdótico (o intrascendente) como géneros emergentes del periodismo deportivo. La única contribución en esta obra respecto de la radio es el texto de Antonio Checa Godoy (2005), quien tras documentar la oferta radiofónica deportiva española desde sus orígenes hasta Internet, caracteriza la cobertura de los eventos deportivos por parte de la industria de la radio.

Dentro de la misma obra se analiza la oferta de contenidos de los MCM por parte de Joaquín Marín Montín (2005d), quien además de ofrecer una tipología de los programas deportivos, aborda la caracterización de la producción fílmica del deporte donde el género documental destaca por encima de la ficción (Marín, 2005c). Asimismo hay dos contribuciones respecto de la dimensión económica con base en la lógica de la mercadotecnia y la publicidad. Santiago Romero (2005), analiza la relación del deporte de alto rendimiento con el mercado y las formas de patrocinio (televisión y MCM) que proyecta la figura del deporte/espectáculo; por su parte, Jorge Fernández (2005) explora el caso de la marca Nike como producto simbólico y construcción actitudinal en el mundo deportivo contemporáneo. 
Finalmente, el libro contiene tres contribuciones sobre nuevas tecnologías y las caricaturas niponas: por un lado, el capítulo de Juan De Pablos Pons (2005), quien ofrece coordenadas precisas para la comprensión del proceso de inmersión de la informática o computación en el campo deportivo; el texto de Alfonso Boullón (2005) sobre la relación de los videojuegos y el deporte a través de las diversas prácticas y contenidos deportivos desarrollados por la industria cultural y mediática; y Jesús Jiménez (2005) aborda la presencia del deporte en el cómic, un género narrativo con arraigo en Japón en términos históricoculturales.

Sudamérica tiene una amplia trayectoria de estudios e investigaciones. Por ejemplo, el número especial "Fútbol y Comunicación" publicado por la revista Contratexto (Universidad de Lima) en 1999, estuvo dedicado al futbol desde la perspectiva de la comunicación, destacando los abordajes semióticos y el análisis mediático (Alabarces, 2000). Precisamente el argentino Pablo Alabarces es un investigador de referencia con una amplia reflexión sostenida sobre el deporte en general y el futbol en particular, y el lugar que ocupan los MCM. De 1998 data “¿De qué hablamos cuando hablamos de deporte?” en la revista Nueva Sociedad, artículo en el que señala la desatención sobre el fenómeno deportivo por parte de las ciencias sociales en América Latina, la deportivización de la agenda cotidiana donde el deporte (espectáculo) es una mercancía masmediática y elemento central de la industria cultural, así como un referente cultural de los procesos de significación construidos en la interacción social (Alabarces, 1998).

También coordinó Peligro de Gol. Estudios sobre el Deporte y Sociedad en América Latina. Su capítulo "Los estudios sobre deporte y sociedad: objetos, miradas, agendas" (Alabarces, 2000) ofrece una cartografía retrospectiva y un plano prospectivo para transitar la genealogía sudamericana sobre deporte, que posibilita la ubicación de los avances de investigación desde la comunicación. Recientemente participó en el dossier "Deporte, Cultura y Comunicación" de la revista mexicana $R a-$ zón y Palabra con el artículo "El deporte en América Latina", que sitúa dentro del marco histórico-cultural de la región el papel de los MCM en la popularización del deporte (Alabarces, 2009). 


\section{APROXIMACIÓN A LOS ESTUDIOS SOBRE DEPORTE Y COMUNICACIÓN EN MÉXICO}

La investigación mexicana en deporte y comunicación es incipiente, gira básicamente en torno al futbol y ha estado desarrollada por parte de un grupo de investigadores que han ido adquiriendo visibilidad institucional. Los primeros esfuerzos de sistematización de la investigación en el tema se deben a Enrique Rivera Guerrero y Samuel Martínez, de la la Universidad de Sonora y la Universidad Iberoamericana (UIA) respectivamente; juntos constituyeron el grupo de investigación Comunicación y Deporte de la Asociación Mexicana de Investigadores de la Comunicación en la década de 2000.

En 2001 publicaron el artículo "Deporte y comunicación en México: autores y temáticas" en la revista Educación Física y Deportes de Argentina, texto en el que presentaron un breve balance descriptivo de la investigación en México con base en 37 productos académicos: libros, tesis, monografías, ponencias, artículos publicados en revistas y bases de datos electrónicas. Destaca que del total de la producción académica, $48.6 \%$ remite a trabajos recepcionales, principalmente en nivel licenciatura (14), y que los medios de comunicación y el deporte hayan sido la temática más abordada en el corpus revisado, particularmente en torno a la prensa (14) y la televisión (10) (Rivera \& Martínez, 2001). Respecto de este último hallazgo es pertinente señalar que la centralidad de los MCM como objeto de estudio en la investigación no alude solamente al tema deporte y comunicación sino que se constituye como una característica histórica que forma parte de la consolidación del entendimiento de los MCM en su dimensión de difusión de información dentro del campo de la comunicación en México (Galindo \& Rizo, 2005).

La anterior premisa también fue posible observarla en la revisión de literatura producida sobre deporte y comunicación en México realizada como parte del proceso de elaboración de este artículo, exploración que nos permitió organizar los textos con base en su información bibliográfica y, en un segundo nivel de profundidad, su genealogía y contenido. 5

5 La exploración de la producción académica mexicana sobre el tema la realizamos durante enero y julio de 2011 en el Catálogo de la Documenta- 
El cuerpo de análisis está constituido por la sistematización de 33 productos académicos en formato de libro, capítulos de libro, artículos y tesis de maestría.

La década de 1990 ha sido la más prolífica con 16 productos académicos, posteriormente aparecen la década de 2000 con diez; 2010 con seis, y 1980 con uno. Con relación al lugar de publicación de los textos destaca el Distrito Federal con $72.7 \%$ del total de productos académicos (24), Guadalajara con dos y Colima, Mexicali, Toluca y Veracruz con uno respectivamente (cabe destacar que tres artículos elaborados en Distrito Federal y Veracruz fueron publicados en Lima y Buenos Aires). En principio, el registro de la producción campal en términos estructurales con relación al lugar coincide con lo señalado por Rivera y Martínez (2001), y en general con las revisiones generales que atañen a otras líneas de investigación, dado que el Distrito Federal destaca como ciudad/ referente del quehacer de la investigación en comunicación en el país.

En la investigación mexicana del deporte y la comunicación destaca el formato de artículo con 25 productos académicos por encima de capítulos de libro (5); tesis de maestría (2) y libro (coordinado) (1). Se trata de una distribución similar a la registrada por Rivera y Martínez (2001) y esta inclinación de los autores(as) por el género de artículo tal vez se deba a que las publicaciones en revistas científicas permiten

ción de Ciencias de la Comunicación (CC-DOC) del Instituto Tecnológico y de Estudios Superiores de Occidente (ITESO) y del Consejo Nacional de Ciencia y Tecnología (CONACYT) dirigido por Raúl Fuentes Navarro, y en la Red de Revistas Científicas de América Latina y el Caribe, España y Portugal (Redalyc); en las principales revistas de investigación del campo donde destacan Comunicación y Sociedad de la Universidad de Guadalajara (UdeG), Revista Mexicana de Comunicación de la Fundación Manuel Buendía, Razón y Palabra del Instituto Tecnológico y de Estudios Superiores de Monterrey (ITESM) y Estudios sobre las Culturas Contemporáneas de la Universidad de Colima, así como en obras de sistematización documental como La Investigación Académica sobre Comunicación en México. Sistematización Documental 1995-2001 de Raúl Fuentes (2003) y La Comunicación en México. Una Agenda de Investigación coordinada por Aimée Vega (2009). 
tener productos materializados a corto plazo y bajo procedimientos rigurosos de dictaminación. En ese sentido, quizá la falta de conformación de grupos de trabajo e investigación sobre el tema ha influido en la producción de libros y capítulos de libro debido a que la colaboración y el diálogo académico generalmente permiten dar volumen al trabajo científico.

Con relación al contenido de los productos académicos publicados en México destaca el tema de los medios de comunicación como categoría general con 16 publicaciones, el resto de las categorías son identidad (4), entretenimiento (3), cultura (2), investigación en comunicación (2), consumo cultural (1), educación (1), espacio social (1), familia (1), opinión pública (1) y sentido social (1). En torno a categorías específicas los temas remiten a la construcción de identidades, afición y conocimiento sobre futbol, contenidos deportivos en Internet y televisión, futbol y nación, crónica deportiva, efectos del futbol en la familia, enseñanza del deporte (futbol americano femenil), futbol e Internet, cine, cultura y entretenimiento, géneros deportivos en televisión, historia del deporte, identidad regional, consumo cultural y procesos de comunicación, investigación sobre entretenimiento y en comunicación en general, prácticas deportivas y espacio social, prensa y sentido social, futbol y género en la prensa, representaciones del futbol en MCM, televisión, audiencias y videojuegos.

Una de las publicaciones pioneras en deporte y comunicación es el artículo "El deporte en la prensa de Guadalajara. Una exploración sospechosa" de Juan Carlos Ramírez publicado en 1986, texto en el que se exponen los primeros resultados de un estudio que rastrea el sentido social del deporte que produce la prensa en Guadalajara. Posteriormente se publicó el artículo "Piques, amagos, frenos de la crónica deportiva en México" de Fernando Mejía (1992), quien revisa la historia del periodismo deportivo en México desde la década de 1920. Otros de los artículos publicados en la primera parte de la década de 1990 son sobre futbol y opinión pública en contexto de crisis de Gilberto Fregoso (1993); sobre representaciones del futbol en los medios de comunicación (televisión, radio y prensa) de Federico Medina (1995), y sobre el uso de dispositivos técnicos en la enseñanza del deporte de Alejandro Acuña (1995). 
En la segunda parte de la década de 1990 aparecen las contribuciones de Claudia Benassini (1996a, 1996b) en torno al deporte y la televisión a partir de la caracterización del género deportivo y sus abordajes históricos, sus reflexiones además enfatizan la poca exploración de este objeto de estudio en el ámbito de la comunicación. Benassini también publicó tres artículos sobre el papel de Internet en la investigación sobre televisión, donde el futbol representa un objeto de estudio concreto (1998a), con relación a la presencia del futbol en Internet (1998b) y sobre este medio de comunicación emergente como espacio de expresión social (1999). En este tiempo Carmen Gómez Mont (1996) publicó un artículo sobre la posibilidad de reconocer los eventos deportivos mediatizados como referentes en la construcción de identidades a través de la experiencia de los Juegos Olímpicos. Un año después José Jara (1997) publicó sobre audiencias y el género deportivo en televisión, y al final de la década Enrique Rivera publicó dos trabajos relativos al deporte e identidad regional (1999a) y consumo cultural y la afición deportiva (1999b).

En la década de 2000 se publica una de las primeras sistematizaciones de la producción académica sobre deporte y comunicación en México, el artículo "Deportes y comunicación en México: autores y temáticas" de Enrique Rivera y Samuel Martínez (2001) que registró las características principales de los avances científicos en torno al tema, enfatizando la premisa señalada por Claudia Benassini (1996a, 1996b) en años anteriores sobre la falta de estudios que abordaran este objeto de estudio, develó algunos puntos clave de las dimensiones estructural y de contenido del cuerpo de productos publicados.

En 2000 se elaboró una tesis de maestría en la Universidad Nacional Autónoma de México (UNAM) con relación a la televisión como escenario de poder económico y político donde se realiza un análisis comparativo de contenido de la televisión pública y la comercial frente al terremoto de 1985, el mundial de futbol de 1986 y las elecciones federales de 1988 (Martínez Merling, 2000). Tres años después se publicó un artículo sobre la relación de prácticas deportivas de futbol y el espacio social en donde tienen lugar diversos procesos de estructuración, uso, significación y representación (Vergara, 2003). 
En la segunda parte de la década, Jorge Meneses (2008) publicó un artículo sobre futbol y afiliaciones en el que explora el sentido de pertenencia de los aficionados a sus equipos desde de la socialización, el ritual y la identidad como elementos centrales. En 2009 destacan seis artículos publicados en el dossier "Deporte, Cultura y Comunicación" de Razón y Palabra en torno a la relación del deporte con el cine (Colin, 2009), los videojuegos (Garduño \& Garduño, 2009; Peláez, 2009), el negocio del periodismo deportivo (Pérez, 2009) y la afición en el futbol observada desde la identidad (Rodelo \& Armienta, 2009), además del texto de Pablo Alabarces (2009) mencionado en el apartado anterior sobre la popularización del deporte en la América hispanófona y lusófona en donde los MCM resultaron actores clave.

Finalmente, los registros más recientes remiten al libro Fútbol, Espectáculo, Cultura y Sociedad, coordinado por Samuel Martínez (2010a) como producto de las múltiples sesiones de trabajo del diplomado "Fútbol-espectáculo, cultura y sociedad. Una revisión crítica al negocio mundial" realizado por el Departamento de Comunicación de la UIA de la Ciudad de México. En esta obra destacan tres productos concretos: la introducción a la obra elaborada por Martínez (2010b) que presenta reflexiones en torno a la sociedad deportivizada, el futbol como espectáculo y los estudios sobre futbol en América Latina, y otro capítulo de su autoría en el que desarrolla el tema del futbol y la industria del entretenimiento (Martínez, 2010c), así como el texto de Jesús Galindo (2010) de impronta comunicacional en donde propone un esbozo de lo que se puede estudiar a partir del deporte para intervenir desde las prácticas deportivas sobre las relaciones sociales.

\section{FUTBOL/OCIO, FUTBOL/NEGOCIO}

El deporte y el futbol mediáticos que atraen la atención de periodistas, cámaras y una amplia gama de televidentes, lectores y radioyentes que aseguran significativas cuotas de rating y de mercado publicitario, constituyen una realidad deportiva promovida por complejas alianzas de intereses que vinculan principalmente a las federaciones, los clubes, los estados y las empresas o los MCM. El fenómeno creado se impone 
cotidianamente por el negocio multimillonario que implica. Para algunos analistas, esta convergencia del espectáculo deportivo con la técnica sobrehumana ha sido el espectador/pasivo, el totalitarismo de estadio y un multifacético catálogo de nuevas formas de sumisión modernas. A esta conclusión llegó el filósofo Rafael Argullol (1992) en el artículo "Estética del juego" cuando hizo esta cruda lectura: "El totalitarismo del estadio, multiplicado ilimitadamente por los medios de comunicación, es una de las facetas más aceptadas, pero no por ello menos alarmantes, de la sumisión moderna" (s. p.).

Una vez más encontramos el cóctel de totalitarismo, MCM y opio del pueblo como pócima de la "sumisión moderna". La sociedad occidental en sus facetas más emblemáticas (industrial, postindustrial, postcapitalista, mediática/electrónica, etc.) y sus actores característicos (homo videns, homo faber, homo tecnicus, homo laborans, homo loquens, homo performator, e-homo, etc.) promueve multitud de formas de prácticas deportivas. En parte por eso, los MCM, los grandes clubes y las federaciones se han aliado para crear eventos extraordinarios con un potencial fuerte de plusvalía. Desde la contratación de grandes estrellas o la organización de torneos con los mejores, hasta la instalación de todo tipo de infraestructuras (grúas, andamios, focos, cámaras, unidades móviles, computadoras) para dar cuenta lo más espectacularmente posible del evento. Por ejemplo, el uso de software avanzado, tecnología digital y cámaras phantom que permiten la repetición de la jugada con una lentitud y riqueza de apreciación que en sí mismo es un espectáculo dentro del espectáculo. Y, paralelamente, formando parte del espectáculo global, también acuden vendedores de bufandas, posters, camisetas, refrescos, tortas, etcétera.

Esta alianza entre el ocio y el negocio, entre el deporte/espectáculo y las millonarias ganancias no se explican sin la inversión en publicidad y la performance deportiva mediatizada. Este big bussines lo hacen posible las tecnologías televisivas y de edición que han manufacturado el espectáculo deportivo y logrado un producto final con un tipo de matices diferentes al del partido en vivo o in situ, como la repetición de jugadas, la imagen congelada o el uso de varias cámaras que ofrecen distintas perspectivas o primeros planos de una misma acción o jugador. Esta dimensión televisiva se mezcló con otros ingredientes que ya 
están presentes en toda competición deportiva y que captan la atención o despiertan interés. Pero esto implica que los clubes de futbol, para mantener su competitividad y atractivo, deben estar constantemente invirtiendo y endeudándose.

A este respecto, Gerhard Vinnai (1974), desde su óptica de sociólogo marxista, hizo en su día varios señalamientos acertados y vigentes sobre los problemas económicos que amenazaban al futbol, y el tiempo le ha dado la razón. Señaló que el endeudamiento de los clubes de futbol es consustancial a la lógica del sistema capitalista. Lo que a su vez explica que la veta de negocio televisión/futbol haya sido exprimida ininterrumpidamente y siga rindiendo beneficios. Vinnai (1974) ya dijo que los clubes de jugadores profesionales son empresas económicas profesionales del sector de la prestación de servicios, que venden las exhibiciones de futbolistas, en cuanto mercancía, a un público que las consume. Hoy esto es más que evidente y los clubes de futbol profesional solo son viables como actividad empresarial, en la medida que sean capaces de reducir la actividad deportiva a la condición de una mercancía exitosa deportiva y comercialmente.

Las consecuencias son múltiples. El mismo Vinnai (1974) denunciaba que la retransmisión televisada de partidos de futbol producía el hábito de verlo cómodamente, lo cual iba en detrimento del gusto por ver el futbol amateur en directo. "El fútbol profesional ha condenado al fútbol aficionado a una vida irreal tanto en el aspecto deportivo como en el económico" (p. 69). Esto está pasando actualmente en México con la lucha libre, desplazada por programas de lucha estadounidense emitidos por Televisa. Otro ejemplo es la venta de clubes (franquicias) que implica cambiar de ciudad sede, como el Necaxa o el Atlante en México, despreciando o cuestionando el arraigo y el sentimiento identitario que emana de su cuna urbana de origen. También hubo aficiones que vivieron la inserción publicitaria en la camiseta del club como un ultraje a los colores (hoy ya forma parte natural del equipaje). El mismo FC Barcelona hizo gala de no manchar su camiseta, sus colores, con ningún tipo de publicidad comercial; durante décadas solo lució el logo discreto de la marca deportiva que manufactura sus prendas, o el igual de discreto logo de la televisión autonómica catalana TV3, y en los últimos años la gratuita de UNICEF visible en el pectoral. Hasta que en 
2011 ha insertado la de Qatar Foundation y desplazado la de UNICEF a la parte inferior trasera de las camisetas o playeras.

No obstante, la convergencia antes mencionada también debe remitir a la representación del vínculo entre deporte y comunicación/ MCM desde la dimensión de las audiencias activas, premisa construida a través de los avances de investigación en los estudios de recepción (Orozco, 1994). En ese sentido, además de la participación de las audiencias en la dinámica de las fuerzas de la oferta y la demanda de la industria de los MCM bajo la impronta del consumo, es necesario considerar que el proceso de recepción, apropiación y uso de mensajes se redefine en la complejidad de los escenarios en los que los miembros de la audiencia interactúan con otros. Por tanto, la actividad de las audiencias frente a las pantallas que transmiten y recrean el espectáculo deportivo, que confronta la idea del espectador pasivo, es posible observarla en el tiempo concreto de estar frente a la televisión pero también en los itinerarios de la vida cotidiana en que los televidentes del futbol discuten, conversan, recuerdan y sueñan a partir del resultado deportivo del fin de semana. Esto es, los significados socioculturales en juego en la interacción comunicativa que es posible observar en el trabajo, las escuelas, los bares o en las redes sociales como Facebook y Twitter, así como en los foros de las páginas deportivas en línea.

De esta manera el fenómeno del futbol mediatizado alude a la complejidad de una relación entre la industria cultural y las expresiones diversas de las audiencias, en donde más que hablar de amplios márgenes de libertad o constricción en la relación MCM/sujeto, la aproximación a este objeto de estudio debe apuntar al reconocimiento de ciertos factores o mediaciones (individuales, institucionales, situacionales, estructurales y técnicos) que inciden en mayor o menor medida en el proceso de la recepción televisiva (Orozco, 1994), para el caso que nos ocupa, concretamente del deporte y el futbol.

\section{CONCLUSIONES}

Es evidente la existencia de un compromiso en el quehacer de la investigación del futbol y la comunicación en México que, al igual que en otras disciplinas de las ciencias sociales y humanidades, no han eclo- 
sionado como lo hicieron en otras tradiciones académicas hace décadas. Para el caso del futbol, sin duda el espectáculo mediatizado por excelencia, este sugiere la exploración de una diversidad de dimensiones factibles de construirse como objetos de estudio. Algunos de los elementos que proponemos para la confección de una agenda a futuro de investigación remiten a tres campos principalmente:

1. Estudiar la formación de la afición al futbol (in situ y mediadas tecnológicamente) para conocer los sobrepesos de los factores que configuran la identidad de los seguidores de los equipos a escala regional, nacional y global (las afiliaciones a los Xoloitzcuintles en la frontera norte, las Águilas del América o al Barcelona en todo México), pero también con relación al género (las masculinidades o lo femenino en la tribuna), la clase social (la virtual oposición entre los Rayados y los Tigres en la ciudad de Monterrey) y la etnicidad (la experiencia identitaria del futbol en Chiapas y el sureste del país, con los Jaguares).

2. Aproximarse a los procesos de recepción e interacción de contenidos deportivos por parte de los aficionados en plataformas inter y trans mediales que incorporan la televisión, el Internet y los dispositivos móviles (desde la plataforma digital e interactiva de Televisa Deportes hasta la participación de usuarios amateurs en foros o blogs) para analizar las formas emergentes de participación en el fenómeno del futbol mediatizado.

3. Por último, ante la concentración de algunos agentes de las telecomunicaciones en la producción y distribución de bienes mediáticos (Televisa o TV Azteca), proponemos acercarse a la relación de las industrias culturales (MCM) y el futbol desde la economía política de la comunicación. Hay que seguir ahondando en aquellos dispositivos (Foucault) tecno/mediáticos y comerciales por los cuales la alianza con el futbol profesional o FIFA logra mantener el negocio e incluso acrecentarlo; los usos socioculturales en general y los políticos en concreto del futbol mediático; los estilos de reproducción mediática del espectáculo deportivo como parte del show; la influencia del futbol televisado en los estilos y estética del juego, o los frentes de interacción común entre espectáculo futbolístico y empresas mediáticas para mantener el negocio. 


\section{Bibliografía}

Acuña Limón, A. (1995). Actividades de orientación y el uso de videodisco interactivo en la promoción de la motivación para el aprendizaje. Cuadernos de Comunicación y Prácticas Sociales, 7, 79-94.

Alabarces, P. (1998). ¿De qué hablamos cuando hablamos de deporte? Nueva Sociedad, 154, 74-86.

Alabarces, P. (2000). Los estudios sobre deporte y sociedad: objetos, miradas, agendas. En P. Alabarces (Comp.), Peligro de gol. Estudios sobre deporte y sociedad en América Latina (pp. 11-30). Buenos Aires, Argentina: CLACSO.

Alabarces, P. (2002). Fútbol y patria. El fútbol y las narrativas de la nación en la Argentina. Buenos Aires, Argentina: Prometeo Libros.

Alabarces, P. (Comp.). (2003). Futbologías. Fútbol, identidad y violencia en América Latina. Buenos Aires, Argentina: CLACSO.

Alabarces, P. (2009). El deporte en América Latina. Razón y Palabra, 69. Recuperado el 1 de junio de 2011 de http:/www.razonypalabra.org. $\mathrm{mx} /$ EL\%20DEPORTE\%20EN\%20AMERICA\%20LATINA.pdf

Alabarces, P. (2010). Entre la banalidad y la crítica: perspectivas de las ciencias sociales sobre el deporte en América Latina. En S. Martínez (Coord.), Fútbol, espectáculo, cultura y sociedad (pp. 1-30). México, D.F.: UIA.

Alcoba, A. (2005). Fotografía deportiva. En J. Marín (Coord.), Comunicación y deporte. Nuevas perspectivas de estudio (pp. 24-41). Sevilla, España: Comunicación Social.

Alonso, G. (1995). Deporte y producción de sentido: estudio sobre un club de fútbol aficionado. Tesis de doctorado no publicada, Departament d'Antropología Social i Història d'Amèrica i Àfrica, Facultat de Geografia i Història, Universitat de Barcelona, Barcelona, España. Alonso, G. \& Escala, L. (Coords.). (2012). Offside/Fuera de lugar. Fútbol y migraciones en el mundo contemporáneo. México: AM Editores/COLEF.

Angelotti, G. (2010). Chivas y Tuzos. Íconos de México, identidades colectivas y capitalismo de compadres en el fútbol nacional. México, D.F.: COLMICH.

Aparicio, D. (1994). Deportes y medios de comunicación. Telos, 38. Recuperado el 4 de julio de 2011 de http://sociedadinformacion. 
fundacion.telefonica.com/telos/anteriores/num_038/cuaderno_centrall.html

Arazadi, J. (1990, 17 de septiembre). Deporte y fascismo. El País. Recuperado el 16 de enero de $2013 \mathrm{http} / /$ elpais.com/diario/1990/09/17/ opinion/653522410_850215.html

Archetti, E. (1985). Fútbol y ethos. Buenos Aires, Argentina: FLACSO.

Archetti, E. (2001). El potrero, la pista y el ring. Las patrias del deporte argentino. Buenos Aires, Argentina: FCE.

Argullol, R. (1992, 30 de julio). Estética del juego. La Vanguardia. Sección Opinión.

Barreau, J. J. \& Morne, J. J. (1991). Epistemología y antropología del deporte. Madrid, España: Alianza/CSD.

Benassini, C. (1996a). Los deportes por televisión. Revista Mexicana de Comunicación, 45, 43-44.

Benassini, C. (1996b). Deporte y televisión: necesidad de acercarse a un binomio poco explorado. Espacios de Comunicación, 1, 35-54.

Benassini, C. (1998a). Internet y televisión fútbol y telenovelas. Razón y Palabra, 11. Recuperado el 12 de julio de 2011 de http://www. razonypalabra.org.mx/anteriores/n11/benas $11 . h t m l$

Benassini, C. (1998b). Espectáculos televisivos en la red electrónica. Revista Mexicana de Comunicación, 55, 15-17.

Benassini, C. (1999). Ciberhinchas, ciberaficionados, ciber-tifosi: Internet, nuevo espacio de expresión futbolera. Contratexto, 12, 125-150.

Bernstein, A. \& Blain, N. (2002). Sport and the media: The emergence of a major research field. Sports in Society, 5 (3), 1-30.

Blaine, D. P. (1840). An encyclopedia of rural sports: or, a complete account, historical, practical, and descriptive, of hunting, shooting, fishing, racing, and other field sports and athletic amusements of the present day. Londres, Inglaterra: Longman, Orme, Brown, Green and Longmans.

Blanchard, K. \& Cheska, A. (1986). Antropología del Deporte. Barcelona, España: Bellaterra (Trabajo original publicado en 1985).

Boullón, A. (2005). Los videojuegos y sus relaciones con prácticas y contenidos deportivos. En J. Marín (Coord.), Comunicación y deporte. Nuevas perspectivas de estudio (pp. 42-63). Sevilla, España: Comunicación Social. 
Bouet, M. (1968). Signification du sport. París, Francia: Editions Universitaires.

Bourg, J. F. \& Nys, J. F. (1994). Economía del deporte y de la televisión. Telos, 38. Recuperado el 4 de julio de 2011 de http://sociedadinformacion.fundacion.telefonica.com/telos/anteriores/num_038/ index_038.html?cuaderno_central.html

Boyle, R. \& Haynes, R. (2009). Power play: Sport, the media and popular culture. Edinburgh, Inglaterra: Edinburgh University Press (Trabajo original publicado en 2000).

Briggs, A. \& Burke, P. (2002). De Gutenberg a Internet. Una historia social de los medios de comunicación. Madrid, España: Taurus.

Brohm, J-M. (1982). Sociología política del deporte. México: FCE.

Carroggio, M. (1994). Patrocinio, comunicación y deporte. La audiencia, un oro que fusiona tres sectores. Telos, 38. Recuperado el 4 de julio de 2011 de http://sociedadinformacion.fundacion.telefonica. com/telos/anteriores/num_038/index_038.html?cuaderno_central. html

Checa Godoy, A. (2005). La radio deportiva al inicio del siglo XXI. En J. Marín (Coord.), Comunicación y deporte. Nuevas perspectivas de estudio (pp. 64-77). Sevilla, España: Comunicación Social.

Colin, J. (2009). El cine mexicano y el fútbol: una cronología de Los hijos de Don Venancio hasta Atlético San Pancho. Razón y Palabra, 69 (Dossier Deporte, cultura y comunicación). Recuperado el 12 de julio de 2011 de http://www.razonypalabra.org.mx/EL\%20CINE\%20 MEXICANO\%20Y\%20EL\%20FUTBOL\%20UNA\%20CRONOLOGIA $\% 20 \mathrm{DE} \% 20 \mathrm{LOS} \% 20 \mathrm{HIJOS} \% 20 \mathrm{DE} \% 20 \mathrm{DON} \% 20$ VENANCIO $\% 20$ HASTA \%20ATLETICO\%20SAN\%20PANCHO.pdf

Dalpiaz, J. (2002). Os caminhos e os (des)caminhos em "A Sociedade do espetáculo" para se pensar o futebol brasileiro. FAMECOS: Mídia, Cultura e Tecnologia, 17, 142-152.

Da Matta, R. et al. (1982). Universo do Futebol: Esporte e Sociedade Brasileira. Río de Janeiro, Brasil: Pinakotheke.

Da Matta, R. (2009). Sport in society. An essay on Brazilian football. Vibrant, 6 (2), 98-120.

De Moragas, M. (1994). Deportes y medios de comunicación. Sinergias crecientes. Telos, 38, 58-62. 
De Pablos Pons, J. (2005). Internet y deporte. En J. Marín (Coord.), Comunicación y deporte. Nuevas perspectivas de estudio (pp. 132147). Sevilla, España: Comunicación Social.

Diem, C. (1966). Historia de los Deportes (Tomos I-II). Barcelona, España: Luis De Caralt.

Eitzen, D. (1984). Sport in contemporary society. An Anthology. Nueva York, EE.UU.: St. Martin's Press.

El fútbol y la ley. (2007, 23 de agosto). El País. Recuperado el 4 de julio de 2011 de http://www.elpais.com/articulo/opinion/futbol/ley/ elpepiopi/20070823elpepiopi_1/Tes.

Fábregas, A. (2001). Lo sagrado del rebaño. El fútbol como integrador de identidades. México, D.F.: El Colegio de Jalisco.

Fernández, J. (2005). Deporte y publicidad. El caso Nike. En J. Marín (Coord.), Comunicación y deporte. Nuevas perspectivas de estudio (pp. 99-131). Sevilla, España: Comunicación Social.

Fregoso, G. (1993). Entre el drama de la crisis y el circo futbolero. Aproximación a la opinión pública. Comunicación y Sociedad, 1819, 207-222.

Fuentes, R. (2003). La investigación académica sobre comunicación en México. Sistematización documental 1995-2001. Guadalajara, México: ITESO.

Fuentes, R. (2008). La comunicación desde una perspectiva sociocultural. Acercamientos y provocaciones 1997-2007. Guadalajara, México: ITESO.

Galeano, E. (1990). Memoria del Fuego. III. El siglo del viento. Madrid, España: Siglo XXI.

Galindo, J. (2010). Comunicología, comunicometodología y deporte. Crítica epistemológica de las ciencias y las ingenierías del deporte. En S. Martínez (Coord.), Fútbol, espectáculo, cultura y sociedad (pp. 53-68). México, D.F.: UIA.

Galindo, J. \& Rizo, M. (2005). Bibliografía y comunicología posible. Trayectoria, diagnóstico y configuración de opciones, libros y autores, en la bibliografía en español y en idioma distinto al español. En J. Galindo, T. Karam \& M. Rizo (Coords.), Cien libros hacia una comunicología posible. Ensayos, reseñas y sistemas de información (pp. 35-85). México, D.F.: UACM. 
García, E., De Moragas, M. \& Gómez, M. (1994). El deporte en las televisiones españolas. Un papel creciente en la programación. Telos. Deporte y medios de comunicación, 38. Recuperado el 4 de julio de $2011 \mathrm{de}$ http://sociedadinformacion.fundacion.telefonica.com/telos/ anteriores/num_038/index_038.html?cuaderno_central.html

Garduño, E. \& Garduño, L. (2009). La práctica del deporte a través del WII Nintendo. Razón y Palabra, 69 (Dossier Deporte, cultura y comunicación). Recuperado el 12 de julio de 2011 de http://www.razonypalabra.org.mx/LA\%20PRACTICA\%20DEL\%20DEPORTE\%20 A\%20TRAVES\%20DEL\%20WII\%20NINTENDO.pdf

Gastaldo, É. (2002). Negros jogam, brancos torcem: a ritualização das relaçoes raciais na publicida de da Copa do Mundo. ILHA, 4 (2), 99-110.

Gastaldo, É. (2009). “O país do futebol” mediatizado: mídia e Copa do Mundo no Brasil. Sociologias, 11 (22), 352-369.

Gastaldo, É. (2011). Comunicação e esporte: explorando encruzilhadas, saltando cercas. Comunicação, Mídia e Consumo, 8 (21), 39-51.

Gispert, C. (1981). Enciclopedia Mundial del Fútbol (EMF). Barcelona, España: Océano.

Gómez Mont, C. (1996). Comunicación y deporte: entusiasmos e incomprensiones. Espacios de Comunicación, 1, 55-66.

Harris, J. \& Park, R. J. (1983). Play, games and sport. In cultural contexts. Champaign, IL, EE.UU: Human Kinetics Publishers.

Helal, R. (2011). Futebol e comunicaçao: a consolidaçao do campo académico no Brasil. Comunicação, Mídia e Consumo, 8 (21), 11-37.

Helal, R., Soares, A. J. \& Santoro, M. A. (2004). Futebol, imprensa e memoria. Fronteiras-estudos midiáticos, 7 (1), 61-78.

Jara, J. (1997). Las audiencias de la televisión en español en América Latina. Revista Mexicana de Comunicación, 51, 14-17.

Jiménez, J. (2005). Spokon: el deporte como género narrativo en el manga. En J. Marín (Coord.), Comunicación y deporte. Nuevas perspectivas de estudio (pp. 78-98). Sevilla, España: Comunicación Social.

Krauze, E. (1994, 28 de junio). México en un balón. El País. Recuperado el 16 de enero de 2013 de http://elpais.com/diario/1994/06/28/ opinion/772754409_850215.html

Larson, J. (1994). Los deportes en la era informática. Las tecnologías de la información en las emisiones deportivas. Telos, 38. 
Recuperado el 4 de julio de 2011 de http://sociedadinformacion. fundacion.telefonica.com/telos/anteriores/num_038/index_038. html?cuaderno_central4.html

Luschen, G. (Ed.). (1970). The cross cultural analysis of sport and games. Champaign, IL, EE.UU.: Stipes Publishing.

Magnane, G. (1966). Sociología del deporte. Barcelona, España: Edic. 62 (Trabajo original publicado en 1964).

Marín, J. (Coord.). (2005a). Comunicación y deporte. Nuevas perspectivas de estudio. Sevilla, España: Comunicación Social.

Marín, J. (Coord.). (2005b) Introducción. En J. Marín (Coord.), Comunicación y deporte. Nuevas perspectivas de estudio (pp. 18-23). Sevilla, España: Comunicación Social.

Marín, J. (2005c). El deporte en el cine. En J. Marín (Coord.), Comunicación y deporte. Nuevas perspectivas de estudio (pp. 148-166). Sevilla, España: Comunicación Social.

Marín, J. (2005d). La programación deportiva en televisión. En J. Marín (Coord.), Comunicación y deporte. Nuevas perspectivas de estudio (pp. 167-183). Sevilla, España: Comunicación Social.

Martínez, S. (Coord.). (2010a). Fútbol, espectáculo, cultura y sociedad. México, D.F.: UIA.

Martínez, S. (2010b). Introducción. En S. Martínez (Coord.), Fútbol, espectáculo, cultura y sociedad (pp. 9-26). México, D.F.: UIA.

Martínez, S. (2010c). Fútbol-espectáculo e industria del entretenimiento. En S. Martínez (Coord.), Fútbol, espectáculo, cultura y sociedad (pp. 123-156). México, D.F.: UIA.

Martínez Merling, R. (2000). Televisión: ideología, poder y público en México, 1982-1988. Tesis de maestría no publicada. México: UNAM.

McIntosh, P. C. (1963). Sport in society. Londres, Inglaterra: C.A. Watts Company.

Medina, F. (1995). Los narradores deportivos y sus epopeyas cotidianas. Estudios sobre las culturas contemporáneas, 1 (2), 69-106.

Medina, X. \& Sánchez, R. (Eds.). (2003). Culturas en juego. Ensayos de antropología del deporte en España. Barcelona: Icaria Ediciones/Institut Català d' Antropología.

Mejía, F. (1992). Piques, amagos y frenos de la crónica deportiva en México. Revista Mexicana de Comunicación, 26, 7-13. 
Meneses, J. (2008). El fútbol nos une: socialización, ritual e identidad en torno al fútbol. Culturales, 4 (8), 101-140.

Miller, T. \& Martin, R. (Eds.). (1999). Sportcult. Minnesota, EE.UU.: University of Minnesota Press.

Natan, A. (1958). Sport and society. Londres, Inglaterra: Bowes \& Bowes Publishers.

Norbeck, E. (1986). Introducción. En K. Blanchard \& A. Cheska, Antropología del deporte. Barcelona, España: Bellaterra.

Orozco, G. (1994). La autonomía reflexiva de la audiencia. Implicaciones metodológicas para el análisis de la recepción. En C. Cervantes \& E. Sánchez (Coords.), Investigar la comunicación. Propuestas Iberoamericanas (pp. 182-195). Guadalajara, México: UdeG.

Partisans (1978). Deporte, cultura y represión. Barcelona, España: Gustavo Gili.

Peláez, B. (2009). Fútbol y videojuegos: reinventando el juego. Razón y Palabra, 69 (Dossier Deporte, cultura y comunicación). Recuperado el 12 de julio de 2011 de http:/www.razonypalabra.org.mx/ FUTBOL \%20Y\%20VIDEOJUEGOS\%20REINVENTANDO\%20EL\%20 JUEGO.pdf.

Pérez, I. (2009). El negocio del periodismo deportivo. Razón y Palabra, 69 (Dossier Deporte, cultura y comunicación). Recuperado el 12 de julio de 2011 de http:/www.razonypalabra.org.mx/EL\%20NEGOCIO\%20DEL\%20PERIODISMO\%20DEPORTIVO.pdf .

Peters, J. (1999). Speaking into the air. A history of the idea of communication. Chicago, IL, EE.UU.: University of Chicago Press.

Ramírez, J. (1986). El deporte en la prensa de Guadalajara. Una exploración sospechosa. Renglones, 5, 15-17.

Raney, A. \& Bryant, J. (Eds.). (2006). Handbook of sports and media. Mahwah, NJ, EE.UU.: Lawrence Erlbaum Associates.

Risse, H. (1921). Sociologie des sports. Berlín, Alemania: A. Rener.

Rivera, E. (1999a). Los “tiburones rojos" como identificación sociocultural en los aficionados del fútbol del Puerto de Veracruz. Tesis de maestría no publicada, Universidad Veracruzana, Veracruz, México. Rivera, E. (1999b). México en sus regiones socioculturales deportivas. Contratexto, 12, 221-246. 
Rivera, E. \& Martínez, S. (2001). Deporte y comunicación en México: autores y temáticas. Lecturas: Educación Física y Deportes, 42. Recuperado el 13 de febrero de 2011 de http://www.efdeportes.com/ efd42/mex.htm.

Rodelo, J. \& Armienta, W. (2009). El escuadrón aurinegro: identidad y representaciones en una barra de fútbol (equipo Dorados de Sinaloa). Razón y Palabra, 69. Recuperado el 12 de julio de 2011 de http://www.razonypalabra.org.mx/EL\%20ESCUADR0N\%20AURINEGRO.pdf.

Romero, S. (2005). Deporte rendimiento, espectáculo y patrocinio. En J. Marín (Coord.), Comunicación y deporte. Nuevas perspectivas de estudio (pp. 202-224). Sevilla, España: Comunicación Social.

Rowe, D. (Coord.). (2004a). Critical Readings: Sport, Culture and the Media. Issues in Cultural and Media Studies. Berkshire, Inglaterra: Open University Press.

Rowe, D. (2004b). Introduction: Mapping the media sports cultural complex. En D. Rowe (Coord.), Critical readings: Sport, culture and the media. Issues in cultural and media studies (pp. 1-22). Berkshire, Inglaterra: Open University Press.

Sage, G. (1984). Sport in American society: Its pervasiveness and its study. En D. Eitzen (Comp.), Sport in contemporary society. An Anthology (pp. 4-14). Nueva York, EE.UU.: St. Martin's Press.

Sánchez Ferlosio, R. (1990, 11 de junio). Un espectáculo fascista. El País (p. 10/sección deportes).

Sobrados, M. (2005). Entre la información y la opinión. Una revisión de los principales géneros en el periodismo deportivo. En J. Marín (Coord.), Comunicación y deporte. Nuevas perspectivas de estudio (pp. 184-201). Sevilla, España: Comunicación Social.

Steinitzer, H. (1910). Sport und Kultur: mit besonderer Berücksichtigung des Bergsports. Múnich, Alemania: Deutsche Alpenzeitung.

Thomas, R., Haumont, A. \& Levet, J. L. (1988). Sociología del deporte. Barcelona, España: Bellaterra.

Taylor, E. B. (1879, junio). The history of games. Popular Science Monthly, 15, 225-237.

Thompson, J. B. (1998). Ideología y cultura moderna. México, D.F.: UAM (Trabajo original publicado en 1990). 
Vega, A. (Comp.). (2009). La comunicación en México. Una agenda de investigación. México, D.F.: UNAM/UJAT/UABC/AMIC.

Vergara, C. (2003). Espacio: niveles y configuraciones. En I. Cornejo (Coord.), Texturas urbanas: comunicación y cultura (pp. 189-228). México, D.F.: Fundación Manuel Buendía/UIA.

Vinnai, G. (1974). El fútbol como ideología. Buenos Aires, Argentina: Siglo XXI.

Weber, M. (1985). La ética protestante y el espíritu del capitalismo. Barcelona, España: Orbis.

Wenner, L. (Coord.). (1989). Media, sports and society. Newbury, CA, EE.UU.: Sage Publications.

Fecha de recepción: 19/08/11. Aceptación: 06/03/12. 